UDC 316.4.06

LBC 60.52

\title{
SOCIAL DANGER OF MINORS AS A CHALLENGE TO THE NATIONAL SECURITY OF MODERN RUSSIA
}

\author{
Mikhail V. Gorbachev \\ Lomonosov Moscow State University, Moscow, Russian Federation
}

\begin{abstract}
The socially dangerous situation of minors is one of the most acute and at the same time difficult to solve problems of modern society. In different forms, it takes place in almost all countries of the modern world. The Russian Federation is no exception. The significant economic stratification of Russian society, the growing social inequality, the constant increase in the number of citizens living below the poverty line and a number of other equally important factors create conditions for an increase in the number of minors in a socially dangerous situation. The system of prevention of neglect and juvenile delinquency carries out measures for monitoring, accounting, preventive work with the designated social group. The emphasis is on the socio-economic and socio-psychological consequences of the socially dangerous situation of minors. The socio-political aspects of the socially dangerous situation of minors are hardly taken into account. The article is devoted to the study of the socially dangerous situation of minors through the prism of modern challenges to the national security of Russia. The article examines the reasons for the formation of a socially dangerous situation of minors. The possible consequences of a further increase in the number of minors in a socially dangerous situation were identified and described in relation to public and State institutions. The article identifies the challenges to the national security of modern Russia, which may come from the social environment of minors in a socially dangerous situation. New mechanisms of ensuring national security of modern Russia, taking into account the interests of minors in socially dangerous situation, are conceptualized. The empirical base of the article is the data of the system of prevention of neglect and juvenile delinquency (2017-2018), data of indices of social and economic development of the subjects of the Russian Federation (for the same period of time). The methodological basis of the article is the author's approach, which implies a combination of the theoretical foundations of the system of prevention of neglect and juvenile delinquency with the conceptual provisions of the theory of national security.

Key words: minors, socially dangerous situation of minors, the challenges of national security, structure of national, security system national security.
\end{abstract}

УДК 316.4 .06

ББК 60.52

\section{СОЦИАЛЬНО ОПАСНОЕ ПОЛОЖЕНИЕ НЕСОВЕРШЕННОЛЕТНИХ КАК ВЫЗОВ НАЦИОНАЛЬНОЙ БЕЗОПАСНОСТИ СОВРЕМЕННОЙ РОССИИ}

\footnotetext{
Михаил Валерьевич Горбачев

Московский государственный университет им. М.В. Ломоносова, г. Москва, Российская Федерация

Аннотация. Социально опасное положение несовершеннолетних является одной из самых острых и одновременно сложно решаемых проблем современного социума. В разных формах она имеет место практически во всех странах современного мира. Российская Федерация не является исключением. Значительное экономическое расслоение российского общества, растущее социальное неравенство, постоянное увеличение числа граждан, находящихся за чертой бедности и ряд других, не менее значимых факторов - создают условия для увеличения числа несовершеннолетних, находящихся в социально опасном положении. Система профилактики безнадзорности и правонарушений несовершеннолетних осуществляет мероприятия по
} 
контролю, учету, профилактической работе с обозначенной социальной группой. При этом акцент делается на социально-экономических и социально-психологических последствиях социально опасного положения несовершеннолетних. Социально-политические аспекты социально опасного положения несовершеннолетних практически не учитываются. Статья посвящена изучению социально опасного положения несовершеннолетних сквозь призму современных вызовов национальной безопасности России. В статье исследуются причины формирования социально опасного положения несовершеннолетних. Определяются возможные последствия дальнейшего увеличения числа несовершеннолетних, находящихся в социально опасном положении для общественных и государственных институтов. Идентифицируются вызовы национальной безопасности современной России, которые могут исходить из социальной среды несовершеннолетнихе находящихся в социально опасной ситуации; концептуализируются новые механизмы обеспечения национальной безопасности современной России, учитывающие интересы несовершеннолетних. Эмпирической базой статьи выступают сведения системы профилактики безнадзорности и правонарушений несовершеннолетних (2017-2018 гг.), данные индексов социальноэкономического развития субъектов Российской Федерации (за аналогичный период времени). Методологической основной статьи является авторский подход, подразумевающий сочетание теоретических основ деятельности системы профилактики безнадзорности и правонарушений несовершеннолетних с концептуальными положениями теории национальной безопасности.

Ключевые слова: несовершеннолетние, социально опасное положение несовершеннолетних, вызовы национальной безопасности, структура национальной безопасности, система обеспечения национальной безопасности.

\section{Введение}

С момента публикации романа Ж. Амаду «Капитаны песка» (1937 г.), а затем выхода в прокат художественного фильма Х. Бартлетта «Генералы песчаных карьеров» (1971 г.), прошло более восьмидесяти и сорока пяти лет соответственно. Однако социальные проблемы, выявленные и обозначенные бразильским писателем и американским режиссером, продолжают оставаться актуальными. В большинстве стран современного мира, как относящихся к центру мировой экономической системы, так и входящих в ее полупериферийные и периферийные регионы, фиксируется высокий процент несовершеннолетних, находящихся в социально опасном положении (далее СОП) [Лозовская, Фалалеев 2003, 161]. Россия не является исключением. По данным системы профилактики безнадзорности и правонарушений несовершеннолетних, количество несовершеннолетних на территории Российской Федерации, признанных находящимися в СОП, либо отнесенных к данной категории (в том числе детей, проживающих в семьях, находящихся в СОП), по состоянию на конец 2018 г. - 210167 человек [Ilgova et al. web]. По разным оценкам это составляет в среднем $0.1 \%$ от общей численности населения Российской Федерации и 0.7 \% от численности молодежи в возрасте до 29 лет.
В таких странах как США, Китай, Франция наблюдается похожая ситуация. Усредненный процент несовершеннолетних, находящихся в социально опасном положении, $-0.1 \%$ от общей численности населения $-0.6 \%$ от числа молодых людей в возрасте до 29 лет. Необходимо отметить, что приведенная статистика, как в России, так и в зарубежных странах, получена исходя из действующих методик выявления СОП несовершеннолетнихе которая во многом устарела и требует доработки. Ее необходимо осуществить в соответствие с современным социально-экономическим и социально-психологическими реалиями. В связи с обозначенной выше особенностью, некоторые специалисты полагают, что количество несовершеннолетних, находящихся в СОП, может быть значительно выше, чем заявляется в цифрах официальной отечественной и зарубежной статистики.

Поэтому необходимо определять и исследовать вызовы национальной безопасности современной России, исходящие из среды несовершеннолетних, находящихся в СОП. В то же время обобщение литературы показывает, что концептуализация национальной безопасности на основе индикаторов интересов несовершеннолетних, находящихся в СОП, практически не осуществляется как отечественными, так и зарубежными специалистами. Отдельные аспекты данной проблемати- 
ки частично обозначаются в рамках общей теории национальной безопасности [Mohd et al. 2017]. В частности, изучаются вызовы и угрозы политической стабильности государства, исходящие из молодежной среды [Панов 2010, 19]. Также, некоторые особенности политической социализации молодежи в контексте поддержания политической безопасности и стабильности, интерпретируются в современных социологических теориях [Ковалева 2003, 26]. Однако комплексный подход к изучению СОП несовершеннолетних, формирующего современные и малоизученные вызовы национальной безопасности современной России, не сформировался.

Цель статьи - определить вызовы национальной безопасности современной России, формируемые в рамках социальной среды несовершеннолетних, находящихся в социально опасном положении. Реализация поставленной цели достигается посредством решения следующих задач. Во-первых, выявление и обобщение факторов формирования социально опасного положения несовершеннолетних. Во-вторых, типологизация вызовов национальной безопасности России, исходящих из социальной среды несовершеннолетних, находящихся в социально опасном положении. В-третьих, формулирование общих параметров концептуальной модели национальной безопасности современной России, учитывающей интересы несовершеннолетних, находящихся в социально опасном положении.

\section{Факторы формирования СОП несовершеннолетних в современной России}

Анализ социально-экономического положения 85 субъектов Российской Федерации, за период 2017-2018 гг., по таким показателям как качество жизни (на основе индексов), сведения об уровне безработицы (на основании статистической информации), семейное благосостояние (на основании рейтингов), отчеты региональных комиссий по делам несовершеннолетних и защите их прав - позволяет выделить факторы формирования СОП несовершеннолетних в современной России [Ilgova et al. web]. Выявленные факторы можно распределить по трем основным группам в соответствии с природой их возникновения и внутренним содержанием. А именно: социально-экономические факторы, социально-психологические факторы, социально-культурные факторы.

Первая группа факторов, социально-экономической природы, связана с низкими социально-экономическими показателями развития субъектов Российской Федерации. Они способствуют увеличению числа несовершеннолетних, находящихся в СОП. В частности, в субъектах, входящих в состав Южного федерального округа. В этом регионе нестабильное социально-экономическое положение в 2017-2018 гг. проецировало рост числа несовершеннолетних, находящихся в СОП. Подобная ситуация наблюдалась в Северо-Кавказском и Сибирском федеральных округах [Ilgova et al. web]. По большинству субъектов, входящих в их состав, была обнаружена прямая зависимость между негативными трендами социально-экономического развития и ростом числа несовершеннолетних, находящихся в СОП. Напротив, в Центральном, Приволжском, Уральском и Дальневосточном федеральных округах, где фиксировалась относительно стабильная социально-экономическая ситуация, было зафиксировано снижение или сохранение прежнего числа несовершеннолетних, находящихся в СОП на территориях субъектов, которые входят в данные округа [Ilgova et al. web].

Вторая группа факторов, социально-психологической природы, относится к таким фоновым явлениям как алкоголизм и наркомания, которые оказывают влияние на рост числа несовершеннолетних, находящихся в СОП. Так, на территории Сибирского Федерального округа фиксируется высокий уровень алкоголизации населения [Социально значимые... 2018, 11]. Ряд субъектов, входящих в состав округа, в 2017-2018 гг., входил в группу неблагополучных регионов, характеризующихся максимальным объемом продажи алкоголя, наличием высоких показателей смертности, заболеваемости и преступности, связанных с потреблением спиртных напитков (республики Алтай, Бурятия, Хакасия, Алтайский и Забайкальский края) [Главный нарколог... web]. Что касается наркотической ситуации, то Красноярский край вхо- 
дит в тройку лидеров по количеству несовершеннолетних преступников, обвиняемых в наркопреступлениях [Результаты мониторинга... web]. По количеству изъятой конопли и ее производных в 2017-2018 гг. лидировали Республика Бурятия и Тыва, Красноярский и Алтайский края, Иркутская область [Наркологический рейтинг регионов web]. В этот же период времени на территориях данных субъектов фиксировался рост числа семей, находящихся в СОП, увеличение количества несовершеннолетних, которые также относятся к данной категории. Аналогичные тенденции прослеживались в некоторых субъектах Северо-Западного федерального округа (например, Республика Карелия [В Карелии... web]. Противоположные тенденции проявлялись в Центральном Федеральном округе, где в большинстве субъектов средний и низкий уровень алкоголизации населения являлся фактором снижения, или сохранения в прежних значениях числа несовершеннолетних, находящихся в СОП.

Третья группа факторов, способствующих формированию СОП несовершеннолетних, социально-культурная. Ее формируют географические и культурные особенности субъектов Российской Федерации. А именно, «конфессиональный и этнический состав населения, размер территории субъектов, соотношение сельского и городского населения, количество городов с числом жителей свыше миллиона, наличие/отсутствие специфических молодежных и немолодежных субкультур и контркультур» [Ilgova et al. web]. Кроме того, дополнительным социально-культурным фактором формирования СОП несовершеннолетних является уровень их здоровья. Согласно статистической информации, не более $15 \%$ несовершеннолетних являются полностью здоровыми. Это обстоятельство накладывает значительные ограничения на возможности несовершеннолетних в плане бытового и трудового устройства, вхождения в составы социально значимых групп, продолжения образования, дальнейшего профессионального самоопределения. Действие социально-культурных факторов детерминирующих СОП несовершеннолетних, активно проявляется на территории большинства Федеральных округов Российской Федерации.
Таким образом, социально-экономические, социально-психологические, социальнокультурные факторы оказывают существенное влияние на сохранение на прежнем уровне, увеличение, снижение числа несовершеннолетних, находящихся в СОП. Указанные факторы могут являться основой для выделения и типологизации угроз национальной безопасности России, исходящих из социальной среды несовершеннолетних, находящихся в СОП.

\section{Типологизация вызовов национальной безопасности, исходящих из социальной среды несовершеннолетних, находящихся в СОП}

Вызовы национальной безопасности современной России, формируемые средой несовершеннолетних, находящихся в СОП, могут быть типологизированы по следующим группам. Первую группу составляют вызовы, связанные с растущей криминализацией среды несовершеннолетних, с распространением криминальной культуры (наиболее известное проявление подобной культуры представлено российским неформальным молодежным объединением «арестантский уклад един», которое по оценкам некоторых специалистов «активно пропагандирует в среде несовершеннолетних культурные ценности криминальной среды» [Чернышкова, Дебольский 2016, 41] и соответствующего ей типа поведения. Данные вызовы создают значительную нагрузку на общественные и государственные институты, отвечающие за личную и социальную безопасность. Формируют условия для последующего вовлечения молодых людей в криминальные сферы бизнеса, способствуют игнорированию базовых основ общественной морали и правопорядка. Необходимо подчеркнуть, что эти вызовы, являются наименее изученными, в контексте обеспечения основ национальной безопасности современной России, несмотря на их активное обсуждение как научным сообществом, так и в средствах массовой информации.

Во вторую группу входят вызовы, которые связаны с вовлечением несовершеннолетних, находящихся в СОП в террористическую 
деятельность. Вызовы, относящиеся к данной группе, обусловлены гетерогенной системой ценностных ориентаций молодежи в целом и несовершеннолетних, находящихся в СОП. В контексте неустойчивых ценностных ориентаций несовершеннолетних, их стремлении найти новые основы самоидентификации, значительную опасность представляют зарубежные светские и религиозные организации, пропагандирующие религиозный фанатизм и экстремизм, отрицание правовых норм, неуважительное отношение к основам конституционного порядка, чуждые российскому обществу ценности. Как следствие, в среде несовершеннолетних, находящихся в СОП, создаются деструктивные социальные практики, которые способны значительно изменить характер и направленность устоявшихся форм социальных взаимодействий современного российского общества.

Третью группу, формируют вызовы, имеющие непосредственно политическую направленность. Несовершеннолетние, находящиеся в СОП, могут быть вовлечены не только в криминальную, террористическую, экстремистскую деятельность, но в протестную политическую активность деструктивного характера. «Политический вакуум» социальной среды несовершеннолетних, находящихся в СОП, может быть заполнен деструктивными антигосударственными идеями. Такая политическая ориентация несовершеннолетних, находящихся в СОП, способна сформировать негативный публично-политический фон, подрывающий доверие к легитимным институтам власти со стороны других молодежных групп. Это, в свою очередь, может стать причиной кратковременных политических кризисов, ведущих к существенным социально-экономическим потерям. Данная группа вызовов имеет особенно важное значение в силу того, что она является наименее изученной, в отличие от вызовов первых двух групп. Это проявляется как в теоретических, так и в прикладных исследованиях, которые посвящены вопросам обеспечения национальной безопасности, исходя из вызовов, обусловленных современными тенденциями развития социума. В результате, механизмы противодействия подобным вызовам, проработанные и готовые к применению - отсутствуют.
Думается, что, исходя из общего содержания трех типов вызовов, формирующихся в социальной среде несовершеннолетних, находящихся в СОП, необходимо сформулировать обновленные параметры концептуальной модели национальной безопасности современной России.

\section{Параметры модели национальной безопасности современной России, учитывающей интересы несовершеннолетних, находящихся в СОП}

Потребность создания модели национальной безопасности современной России, учитывающей интересы несовершеннолетних, находящихся в СОП, связана со следующими обстоятельствами. А именно, стратегия национальной безопасности современной России, разработанная до 2020 г., включает в себя комплекс мероприятий, направленных на работу с молодежью, на формирование бесконфликтной и интегрированной молодежной среды. Эти мероприятия призваны обеспечить снижение вызовов и угроз национальной безопасности России по таким направлениям как государственная и общественная безопасность (раздел IV, пункт 2), качество жизни российских граждан (раздел IV, пункт 3) [Стратегия... 2016]. Однако данная стратегия не содержит концептуальных программ, позволяющих осуществлять идентификацию, выявление, объяснения, механизмов, причин и последствий, способов минимизации вызовов национальной безопасности России, исходящих из молодежной среды несовершеннолетних, находящихся в СОП. Также, в отечественной социально-гуманитарной науке подробно изучены большинство «традиционных» [Стратегия... 2016] внутренних и внешних вызов национальной безопасности (религиозные войны, межэтнические конфликты, вооруженный сепаратизм и ирредентизм и многие другие). Исследованы факторы, которые детерминируют их. Однако в современном обществе постоянно генерируются новые вызовы, имеющие отличную от «традиционных» природу и направленность. Многие из них только начинают обрабатываться, систематизироваться и получать должное объяс- 
нение. Одним из таких вызов является особое состояние молодежной среды несовершеннолетних, находящихся в СОП.

Думается, что концептуальную основу модели национальной безопасности России, могут формировать сочетания теоретических принципов функционирования системы профилактики безнадзорности и правонарушений несовершеннолетних с положениями теории национальной безопасности. В таком контексте параметры модели национальной безопасности России (государственная безопасность, общественная безопасность, информационная безопасность, безопасность личности [Стратегия... 2016]), учитывающей индикаторы интересов несовершеннолетних, находящихся в СОП, могут быть представлены следующими позициями.

Во-первых, упреждающий характер концептуальной модели национальной безопасности современной России, предусматривающий выявление и предупреждение новейших вызовов, генерируемых социальной средой несовершеннолетних, находящихся в СОП.

Во-вторых, проектные основы модели, ориентированные на возникающие в современном российском социуме локальные вызовы национальной безопасности.

B-третьих, новые понятия теории национальной безопасности, отвечающие вызовам и угрозам, возникающим в среде несовершеннолетних, находящихся в СОП.

В-четвертых, набор индикаторов интересов несовершеннолетних, находящихся в СОП, необходимый для определения ключевых направлений концептуальной модели национальной безопасности.

В-пятых, обновленные механизмы снижения рисков от возникающих вызовов и угроз в среде несовершеннолетних, находящихся в СОП, в отношении которой, государство, на протяжении длительного периода времени не проводило последовательной политики.

Полагаем, что обновленная концептуальная модель национальной безопасности современной России может быть основана на современных понятиях и категориях, новом структурно-содержательном формате основных проблемных областей, скорректированном типологическом ряде современных вы- зовов и угроз, современных механизмах противодействия им. В результате она будет отвечать существующему социальному запросу, принципам социально-политической целесообразности, условиям обеспечения стабильности и устойчивого развития политической системы.

\section{Выводы}

Проблема определения параметров концептуальной модели национальной безопасности России, учитывающей интересы несовершеннолетних, находящихся в СОП, является стратегически значимой для обретения государством уникальных преимуществ в плане предотвращения современных вызовов национальной безопасности. Концептуальное обоснование содержательной специфики, структуры, направлений, функциональности подобной модели позволит сформировать интегративный и консолидирующий потенциал российского общества. Полагаем, что конструирование такой модели подразумевают выполнение следующих теоретико-практических действий.

1. Социо-политическая интерпретация концепта «несовершеннолетние, находящиеся в СОП».

2. Инкорпорация категорий, связанных с ним в концептуальную структуру национальной безопасности России.

3. Концептуализация идеи создания обновленной концептуальной структуры национальной безопасности России, на теоретическом и программном уровнях, исходя из индикаторов интересов несовершеннолетних, находящихся в СОП.

4. Эмпирическая верификация концептуальной структуры национальной безопасности России на основании данных системы профилактики безнадзорности и правонарушений несовершеннолетних, данных полученных в результате проведения масштабных социологических исследований.

5. Идентификация вызовов национальной безопасности России, исходящих из социальной среды несовершеннолетних, находящихся в СОП.

6. Выработка механизмов работы с подобными вызовами. 


\section{СПИСОК ЛИТЕРАТУРЫ}

В Карелии... web - В Карелии растет уровень «пьяной» подростковой преступности // http:// rk.karelia.ru/ accident/crime/v-karelii-rastetpyanaya-podrostkovaya-prestupnost.

Главный нарколог... web - Главный нарколог Забайкалья: В крае сложная ситуация по алкоголизации // http://zabinfo.ru/143554.

Ковалева 2003 - Ковалева А.И. Концепция социализации молодежи: нормы, отклонения, социализационная траектория // Социологические исследования. 2003. № 1. С. 26-32.

Лозовская, Фалалеев 2003 - Лозовская Е.Г., Фалалеев Ю.В. Технология социальной реабилитации детей, оказавшихся в социально опасном положении, семейными воспитательными группами // Вестник Волгоградского государственного университета. Серия 7, Философия. Социология и социальные технологии. Вып. 3. 2003. C. $161-165$.

Наркотический рейтинг регионов web - Наркотический рейтинг регионов. Где в России кайф ловят? // https://fedpress.ru/news/society/ reviews/1442391772-gde-v-rossii-kaif-lovyatnarkoticheskii-reiting-regionov

Панов 2010 - Панов П.В. Политический порядок и воспроизводство власти: институт преемника // Политическая экспертиза. Политэкс. 2010. T. 6, № 3. C. 19-33.

Результаты мониторинга...web - Результаты мониторинга наркоситуации в Красноярском крае по итогам 2017 года // http://www.krskstate.ru/ dat/bin/art/32097_18_05_11_doklad_o_ narkosituacii_za_2017_dly_publikovaniy_na_sajte.doc (дата обращения: 21.09.2019).

Социально значимые... 2018 - Социально значимые заболевания населения России в 2017 году: стат. материалы. М.: ЦНИИ ОиИЗ, 2018.

Стратегия... 2016 - Стратегия национальной безопасности Российской Федерации. Утверждена Указом Президента РФ № 683 от 31.12.2015 года // СЗ РФ. 2016. № 1 (ч. II).

Чернышкова, Дебольский 2016 - Чернышкова М.П., Дебольский М.Г. Криминальная субкультура в среде несовершеннолетних, содержащихся в местах лишения свободы, и профилактика ее распространения // Прикладная юридическая психология. 2016. №2 (35). С. 41-47.

Mohd et al. 2017 - Mohd, Azizah ; Mahmod, Nik Ahmad Kamal Nik; Mohamed, Ashgar Ali Ali ; Amuda, Yusuf Jelili ; Salleh, Marhanum Che Mohd Protecting children from labor: Muslim scholar's viewpoint and legal provisions in selected Muslim countries // Advanced Science Letters. 2017. № 23 (7) P. 6106-6109.
Ilgova et al. web - Ilgova E.V., Kuznetcova I.O., Gorbachev M.V., Starodumov A.K. Crossregional analysis of demographic, criminogenic, economic, socio-cultural factors impact on delinquency indicators dynamics [Journal of Legal, Ethical and Regulatory. 2019. Vol. 20, iss. 4] // https://www.abacademies.org/articles/ crossregional-analysis-of-demographiccriminogenic-economic-sociocultural-factorsimpact-on-delinquency-indicators-dynamics8563.html.

\section{REFERENCES}

The level of "drunk" teenage crime is growing in Karelia. September 2017. URL: http://rk.karelia. ru/accident/crime/v-karelii-rastet-pyanayapodrostkovaya-prestupnost.

Chief Narcologist of Transbaikalia: The region a difficult situation on alcoholism. January 2017. URL: http://zabinfo.ru/143554.

Kovaleva A.I., 2003. The Concept of youth socialization: norms, deviations, socialization trajectory. Sotsiologicheskie issledovaniia [Sociological Studies], no. 1, pp. 26-32.

Lozovskaya E.G., Falaleev Yu.V., 2003. Technology of social rehabilitation of children in a socially dangerous situation, family educational groups. Vestnik Volgogradskogo gosudarstvennogo universiteta. Seriya 7, Filosofiya. Sociologiya i social'nye tekhnologii, vol. 3, pp. 161-165.

Narcotic rating of regions. Where in Russia the buzz is caught? February 2018. URL: http:// fedpress.ru/news/society/ reviews/1442391772.

Panov P.V., 2010. Political order and reproduction of power: Institute of successor, Political expertise. Politex, vol. 6, no. 3, pp. 19-33.

Results of monitoring of drug situation in Krasnoyarsk region by the results of 2017. May 2017. URL: http://www.krskstate.ru/dat/ bin/art/32097_18_05_11_doklad_o_narkosituac-ii_za_2017_dly_publikovaniy_ na_sajte.doc.

Socially significant diseases of the population of Russia in 2017: Statistical materials. Moscow, Central Research Institute of OIIZ, 2018.

National Security Strategy of the Russian Federation, 2016. Approved by decree of the President of the Russian Federation, no. 683, 31.12.2015. Collection of Laws, Russian Federation, no. 1, Part II.

Chernyshkova M.P., Debolsky M.G., 2016. Criminal subculture among minors held in places of imprisonment, and prevention of its spread. Applied legal psychology, no. 2 (35), pp. 41-47. 
Mohd, Azizah; Mahmod, Nik Ahmad Kamal Nik; Mohamed, Ashgar Ali Ali; Amuda, Yusuf Jelili; Salleh, Marhanum Che Mohd, 2017. Protecting children from labor: Muslim scholar's viewpoint and legal provisions in selected Muslim countries. Advanced Science Letters, no. 23(7), pp. 6106-6109.

Ilgova E.V., Kuznetcova I.O., Gorbachev M.V., Starodumov A.K., 2019. Cross-regional analysis of demographic, criminogenic, economic, socio-cultural factors impact on delinquency indicators dynamics. Journal of Legal, Ethical and Regulatory, vol. 20, iss. 4. URL: https:// www.abacademies.org/articles/crossregionalanalysis-of-demographic-criminogeniceconomic-sociocultural-factors-impact-ondelinquency-indicators-dynamics-8563.html.

\section{Information About the Author}

Mikhail V. Gorbachev, Doctor of Sciences (Politics), Associate Professor, Department of Russian Politics, Lomonosov Moscow State University, Shuvalov's Building, Lomonosov Prospekt, 27, Bld. 4, 119192 Moscow, Russian Federation, ussr-86@mail.ru, https://orcid.org/0000-0002-0006-3875

\section{Информация об авторе}

Михаил Валерьевич Горбачев, доктор политических наук, доцент кафедры российской политики, Московский государственный университет им. М.В. Ломоносова, Шуваловский корпус, Ломоносовский просп., 27, корп. 4, 119192 г. Москва, Российская Федерация, ussr-86@mail.ru, https://orcid.org/0000-0002-0006-3875 